Check for updates

Cite this: J. Mater. Chem. B, 2021 9, 8530

\section{Correction: Poly(acrylic acid)-mediated synthesis of cerium oxide nanoparticles with variable oxidation states and their effect on regulating the intracellular ROS level}

\author{
Xiaohui Ju, ${ }^{\star a}$ Marie Hubalek Kalbacova, ${ }^{\text {bc }}$ Břetislav Šmíd, ${ }^{a}$ Viktor Johánek, ${ }^{a}$ \\ Martin Janata, ${ }^{a}$ Thu Ngan Dinhová, ${ }^{a}$ Tereza Bělinová, ${ }^{d}$ Michal Mazur, \\ Maryna Vorokhta ${ }^{f}$ and Ladislav Strnad ${ }^{g}$
}

DOI: $10.1039 / \mathrm{d} 1 \mathrm{tb} 90156 \mathrm{~g}$

rsc.li/materials-b

Correction for 'Poly(acrylic acid)-mediated synthesis of cerium oxide nanoparticles with variable oxidation states and their effect on regulating the intracellular ROS level' by Xiaohui Ju et al., J. Mater. Chem. B, 2021, 9, 7386-7400, DOI: 10.1039/D1TB00706H.

The authors note a mistake in Fig. 3 in which part b is absent from the advance article. The corrected Fig. 3 is shown below in this correction notice.

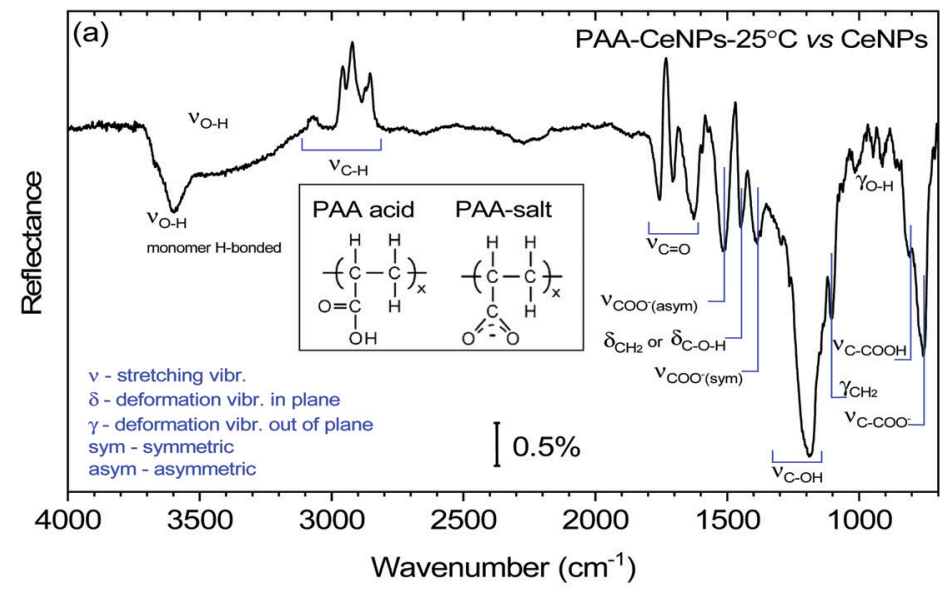

\begin{tabular}{|c|c|c|c|}
\hline (b) & \multicolumn{2}{|c|}{ Peak position } & \multirow[b]{2}{*}{ Peak assignment } \\
\hline $\begin{array}{l}\text { PAA } \\
\text { acid }\end{array}$ & $\begin{array}{l}\text { PAA } \\
\text { salt }\end{array}$ & $\begin{array}{l}\text { PAA- } \\
\text { CeNPs }\end{array}$ & \\
\hline & & 3600 & $\mathrm{OH}$ stretch (mono H-bonded) \\
\hline 1717 & I & $1624-1766$ & $-\mathrm{C}=\mathrm{O}$ stretch (free $\mathrm{COOH}$ ) \\
\hline I & 1562 & 1510 & $-\mathrm{COO}$ stretch (asymmetric) \\
\hline 1455 & 1453 & 1450 & $-\mathrm{CH}_{2}$ or $-\mathrm{C}-\mathrm{O}-\mathrm{H}$ bend \\
\hline / & 1408 & 1390 & $-\mathrm{COO}^{-}$(symmetric) stretch \\
\hline 1265 & / & $1120-1280$ & $-\mathrm{C}-\mathrm{OH}$ stretch \\
\hline \multirow[t]{2}{*}{803} & I & 803 & $\mathrm{C}-\mathrm{COOH}$ stretch \\
\hline & 758 & 758 & C-COO stretch \\
\hline 1 & 154 & 120 & $\Delta v$ (asymmetric - symmetric) \\
\hline
\end{tabular}

Fig. 3 (a) FTIR spectra of PAA-CeNPs $-25^{\circ} \mathrm{C}$ with the CeNPs as a reference. Individual peak assignments are listed in the spectra. The inserts show the PAA structures in an acidic or alkaline environment, corresponding to its ionic and cationic structure. (b) Selected peak assignments are listed in the table. Comparison of FTIR peak assignment for PAA in acidic and alkaline solutions reported previously, and the peak assignment of synthesized PAA-CeNPs-25 ${ }^{\circ} \mathrm{C}$ after subtracting CeNPs as a reference. $\Delta \nu$ is calculated as the peak position differences between asymmetric and symmetric $\mathrm{COO}^{-}$.

The Royal Society of Chemistry apologises for these errors and any consequent inconvenience to authors and readers.

\footnotetext{
${ }^{a}$ Department of Surface and Plasma Science, Faculty of Mathematics and Physics, Charles University, Prague, Czech Republic. E-mail: xiaohui.ju@mff.cuni.cz

${ }^{b}$ Institute of Pathological Physiology, 1st Faculty of Medicine, Charles University, Prague, Czech Republic. E-mail: marie.kalbacova@lf1.cuni.cz

${ }^{c}$ Faculty of Health Studies, Technical University of Liberec, Liberec, Czech Republic

${ }^{d}$ Biomedical Center, Medical Faculty in Pilsen, Charles University, Pilsen, Czech Republic

${ }^{e}$ Department of Physical and Macromolecular Chemistry, Faculty of Sciences, Charles University, Prague, Czech Republic

${ }^{f}$ Department of Geochemistry, Institute of Rock Structure and Mechanics, Czech Academy of Sciences, Prague, Czech Republic

${ }^{g}$ Laboratories of the Geological Institutes, Charles University, Prague, Czech Republic
} 